\title{
Pum! Ou as surpresas do Sr. Artur Azevedo para o palco do século
}

\author{
Tania Brandão
}

Se criarmos um conceito irreverente de peripécia historiográfica para o estudo do teatro brasileiro, caberia a Artur Azevedo (1855-1908) o primeiro papel - ele deveria figurar como herói inconteste e protagonista absoluto. Nenhum outro autor da história de nosso palco sofreu mudança de fortuna tão radical quanto o notável homem de teatro, em nossos estudos de teatro. A progressão de sua trajetória, tensa e sofrida, arrastou-se pelas páginas dos volumes escritos pelos diversos estudiosos; a princípio, a sua situação era negativa, a maioria de suas iniciativas era avaliada de forma desfavorável, como se ele fosse um nefasto vilão. Aqui e ali despontava algum reconhecimento de mérito, mas o sentido dos seus atos, o movimento e o conceito que presidiam os seus textos eram desqualificados com vigor. Sustentou-se até por bastante tempo que ele, líder, culto, bem formado, teria sido o responsável pela destruição de um teatro brasileiro nobre, distinto, de fina extração artística, o teatro de arte que iria conduzir as almas do país a um paraíso cultural autêntico, a civilização. $\mathrm{Ou}$ - falta tão grave quanto a primeira - ele teria impedido que este teatro redentor viesse à luz. Aos poucos, no entanto, a sua sorte foi mudando, até alcançar uma situação, hoje, que, se não atinge a aclamação inconteste, ao menos já é de considerável positividade.

Ao longo de sua vida, marcada pela dedicação total à cena, o autor sofreu ataques permanentes em virtude das peculiaridades de seu talento, voltado para o teatro ligeiro em múltiplas facetas. Os ataques estavam ligados à compreensão do sentido e da definição do teatro dominantes então, derivada, esta compreensão, em certa medida, de concepções do classicismo francês e de uma forma peculiar de avaliar a "boa cultura francesa". O curioso, que é preciso ressaltar, é que o próprio dramaturgo estava preso a este conceito mais tradicional de teatro, o conceito em que ele se formou. Dentre estas concepções, destacam-se em particular: a defesa da hierarquização dos gêneros; a conseqüente classificação da comédia como gênero bastardo, menor, submetido, o próprio gênero, no seu interior, a uma hierarquia de classificação das formas da comédia; a defesa do teatro como instrumento de civilização e de elevação dos costumes; a concepção de que qualquer alusão aos instintos, ao corpo e à sexualidade é prática abjeta; a percepção da sociedade sob uma ótica estamental, segundo a qual tudo o que interessa ou provém do povo é inferior. Por ironia, o modelo do teatro ligeiro, a combatida chacrinha de chirinola, can-can e pernas nuas, era, justamente, francês.

Artur Azevedo tinha extrema habilidade para a comédia, para o retrato crítico e humorado da vida cotidiana ao redor, para a exploração da métrica e da arte de versejar e do uso da música como parte ativa ou expressiva da engrenagem teatral. 
Ao mesmo tempo, era capaz de estruturar um diálogo colorido e eficiente, objetivo, com registro sagaz da linguagem das ruas, trocadilhos, modismos, jogos de sentido e de segundas intenções. Intelectual atuante, bem informado, sabia incorporar aos textos dramáticos os fatos do momento - e o momento significa aqui um vasto olhar ao redor, engloba o histórico, o político, o social, o existencial, o anedótico - revestidos estes fatos de malícia, ironia, crítica, ceticismo. Nada lhe escapava: fosse na cena do Rio miúdo, fosse na alcova ou no púlpito do Rio do poder, fosse na vasta cena do mundo, a vida estava ao seu alcance para ser presenteada às platéias. Ele foi o artífice máximo (e de certa forma anônimo...) da verve carioca, forma existencial que deslumbrou o país no século XX. A mira certeira contava com facilitadores - a freqüência às redações, o emprego público e o acesso às rodas artísticas e intelectuais do seu tempo garantiam um generoso acesso à informação. Mas tais condições estiveram distantes do conforto.

De certa forma, diante de sua arte Artur Azevedo foi vítima e algoz. Se, diante do embate crítico central de sua época, que contrapunha tradição e invenção, elevação e achincalhe, arte sublime e apelação barata, ele foi condenado às vezes com veemência por alguns dos contemporâneos, ele próprio procurou sempre se justificar e se defender, como se fosse pertinente atribuir ao seu métier um rótulo de lamentável negatividade. A dramaturgia seria uma espécie de prostituição, um crime que era preciso justificar até mesmo com alegações morais - a necessidade de sustentar a família...

Assim, em mais de uma ocasião, intelectuais e pensadores investiram contra o autor, acusando-o de contribuir para a morte do teatro brasileiro. O caso sempre citado nas diferentes histórias do teatro desde Múcio da Paixão é o embate entre Artur Azevedo e Cardoso da Motta - o ex-ator, retirado do Rio, investiu contra o dramaturgo imputando-lhe, mais uma vez, a pecha de ter sido o autor da ruína do teatro brasileiro por ter assinado paródias que, a seu ver, foram armas letais contra o bom teatro. A resposta do comediógrafo passa por uma espécie de aceitação parcial dos raciocínios tortuosos: afinal, em lugar de argumentar a favor de sua obra, ele marcha ao lado do ataque contra o teatro que praticava. Chega mesmo a sustentar que tentou o 'bom teatro', mas nos textos de cálculo elevado não obteve nem aclamação suficiente dos doutos e pares, nem proventos expressivos para sustentar a prole.

E se preocupa em passar adiante 'a responsabilidade' pela catástrofe, asseverando que, quando chegou ao Rio de Janeiro, em 1873, várias paródias, assinadas por outros, já tinham instaurado o assalto à cena (A Baronesa de Caiapó, Orfeu na roça, Barba de milho, Cenas da vida do Rio de Janeiro). Portanto, o teatro já estava achincalhado e a crise que todos os espíritos elevados da época (e até de um tanto de tempo depois, diremos nós) localizavam teria sido provocada, a seu ver, pelo gosto do público. A massa ignara teria sido corrompida pelo Alcazar Lyrique, que abrira suas portas ao delírio em 1859 e era tido e havido por todos como o antro de depravação que propôs a exuberância bem sucedida da opereta. Aliás, quanto ao último dos textos citados acima, redigido por seus antecessores, ele assevera que o "mestre 
que mais prezo" teria tido participação na autoria - e seria justamente Machado de Assis, um inimigo do teatro de bambochata e pernas nuas, alguém cuja proximidade ajudou a delinear, para a figura de Artur Azevedo, a inserção ambígua tão peculiar, do flerte com a erudição e o casamento com a transgressão.

A lista de textos de autores e críticos inclinados a restringir a importância e o brilho do teatro de Artur Azevedo pode se estender por várias linhas, todos com argumentações semelhantes e repetitivas. Em tais arrazoados, domina sempre a ressonância de uma idéia de teatro em que só se reconhece valor no universo do trágico e do dramático e, logo abaixo, na elegância da alta comédia. O baixo cômico e a farsa seriam formas grosseiras lamentáveis de representação; o cânone dogmático é a defesa do burilamento literário, o requintado tratamento do texto enquanto palavra vinculada às tradições da história da literatura. Em conseqüência, o investimento na carpintaria da linguagem da cena e na expansão da potência expressiva do ator, a aposta do teatro na diversão pela diversão são heresias inaceitáveis.

O ranço civilizatório formulado pelo século XIX, pespegado ao teatro como se fosse a sua segunda pele, atravessou o seu tempo e chegou à primeira geração moderna, que olhava com desprezo os gêneros ligeiros bastardos - não só a baixa comédia, mas a opereta, a mágica, a revista. De certa forma, lhes faltaria seriedade, eles seriam desviantes em relação a uma missão humana superior. Portanto, Artur Azevedo foi associado, em um primeiro momento moderno, ao que se poderia definir, na visão dos inimigos, como um teatro raso, de sensações superficiais, de tipos e característicos. Algo imediato, que não teria qualquer chance (ou sentido) de ultrapassar o seu tempo.

Neste diapasão, compreende-se os termos fortes, surpreendentes, usados por Décio de Almeida Prado para estudar Artur Azevedo em 1956, em sua $A$ evolução da literatura dramática. Depois de comentar as alegações defensivas cunhadas pelo comediógrafo, as mesmas já citadas, desviando para o público e o clima da época a responsabilidade por sua própria entrega ao universo do riso, o estudioso paulista emite uma avaliação impiedosa:

...na verdade, o gosto da época antes o favoreceu do que o prejudicou: se ele quisesse fazer outra coisa, diferente e melhor, não o conseguiria, porque o seu talento possuía muitas das virtudes secundárias - a facilidade, a naturalidade - e nenhuma das virtudes essenciais do grande escritor. Era desses que só sabem improvisar, cujo primeiro impulso é excelente mas insuscetível de melhoria. Quer lhe dessem vinte dias ou seis meses para desenvolver uma idéia, o resultado seria provavelmente o mesmo. Daí só ter deixado obras menores também nos outros gêneros literários, onde não estava sujeito a ninguém: os seus melhores contos são os mais simples e a parte mais viva de sua poesia a menos ambiciosa (...). Faltava-lhe sobretudo, fôlego: nunca o imaginamos escrevendo um romance ou poema. Daí também não haver progresso, evolução, na sua carreira: as primeiras peças, as primeiras traduções, equivalem às ùltimas. (PRADO, 1956, pp.25-26)

Em textos posteriores, Décio de Almeida Prado $(1986 ; 1999)$ conduz a sua abordagem em outros sentidos - o autor é com certeza o meio mais eficiente para a 
localização da peripécia historiográfica do dramaturgo, em razão de mudanças expressivas em sua forma de avaliação. Com certeza a sensacional montagem de Mambembe, em 1959, com direção e cenografia de Gianni Ratto, não só inaugurou o Teatro dos Sete e festejou o cinqüentenário do Teatro Municipal do Rio de Janeiro, mas também surpreendeu a geração dos primeiros modernos, habituada a torcer o nariz para o velho autor. Ela foi decisiva para a reversão de sua sorte e aparece mesmo em foto no pequeno volume assinado por Prado em 1999.

A encenação de Mambembe foi um divisor de águas, fez com que o autor que se desejava conter no século XIX explodisse a prisão do tempo. É lícito datar deste momento - ironicamente um sucesso de público histórico, retumbante - o árduo caminho de recuperação do autor, sua incorporação ao panteão nobre da literatura brasileira. Mesmo que tenha vivido entre imortais, flanado em meio à mais distinta intelectualidade, figurado no mundo da academia de sua época, Artur Azevedo fora olhado a partir de uma ótica segregacionista da literatura e sob um viés conservador, situação que só bem recentemente começou a ser modificada.

Assim, em Os três gêneros do teatro musicado (1999), tema focalizado com riqueza de informação e olhar generoso, para a escrita da História Concisa do Teatro Brasileiro, Décio de Almeida Prado se estende em duas páginas de estudo do Artur Azevedo revistógrafo, atribuindo-lhe qualidades que, a rigor, denotam justamente fôlego e densidade cultural. Indica mesmo um outro caminho para a análise dos seus textos, a visão de uma opção explícita, calculada, a favor da contaminação entre rua e academia: "Artur Azevedo, o maior entre os revistógrafos do período, aceitava a popularização do teatro efetuada pela revista, mas guardando certa distância, não se igualando jamais ao popularesco." Nesta linha, observa o crítico, tanto ele trazia para a cena temas literários elevados, como empregava, na fala das personagens, os sabores da linguagem coloquial, “....mas sempre como citação, de maneira a não comprometer jamais a sua posição de escritor erudito e gramaticalmente correto."(p.106) Apesar da mudança do olhar, a análise de Prado insiste na indicação de pertencimento da obra a um gênero inferior. E para manter este limite, recorre ao próprio Artur Azevedo:

...Ele morreu, como vivera, com a mão na massa do teatro musicado. Preso, contudo, a fortes preconceitos estéticos, nunca lhe deu o devido apreço. Ao discursar em 1901, durante o enterro de Moreira Sampaio, seu colaborador em inúmeras revistas, queixouse que, "preparando com o estrume da revista do ano o terreno para a plantação da comédia", nenhum dos dois, nem ele nem o amigo falecido, previra que "ficaríamos com as sementes na mão". As sementes já haviam frutificado, em peças como $A$ capital federal ou como Mambembe(...). Mas a natureza mesma do teatro musicado, julgada inferior, não lhe permitia enxergar a realidade teatral plena, tal como ela se desdobra aos olhos de hoje, inteiramente favoráveis às suas modestas, animadas e divertidas burletas. É que nem sempre o gênero, maior ou menor, delimita e define o valor de uma obra. (PRADO, 1999, p. 165)

O texto registra uma mudança de ótica, ainda que relativa, pois o adjetivo modestas e o predomínio de um tom entre bonachão e paternalista pesam em dema- 
sia ao redor do que é dito. Além disso, é preciso destacar o incomodo que é o uso das declarações do autor como armas contra a sua obra - um caso em que a vítima fornece a fatura de provas contra si, para tornar-se réu.

Em texto anterior, posfácio à edição comentada de O Tribofe, de Rachel Teixeira de Valença (1986), a mutação já estava clara. Em lugar de um julgamento presidido pelos valores da literatura, o articulista constrói uma detalhada descrição do processo de escrita de Artur Azevedo, considerando-o uma orientação estreita e radical para as necessidades do teatro, muito embora parta do princípio que era o caso de um "teatro comercial que não se envergonhava de o ser, procurando tirar o melhor partido da submissão à bilheteria”...

Para tanto, as peças eram concebidas para companhias e públicos determinados, os papéis eram com freqüência arquitetados para determinados intérpretes ou desenhados conforme as aptidões e especializações dos atores e por aí vai (PRADO, 1986, p.272). O que significa reconhecer uma senda de trabalho específica, alguns graus afastada do descuido e da pressa.

O avanço dos estudos acadêmicos a propósito da revista, com a difusão de textos importantes assinados por Flora Sussekind (1986) e Neyde Veneziano (1991), foi uma etapa importante para a mudança da abordagem da obra de Artur Azevedo. Não será possível fazer, neste artigo, um inventário detalhado das aventuras do autor nos diferentes textos de história. Mas a consideração desta trajetória em seu conjunto, a partir dos exemplos estratégicos escolhidos, viabiliza a constatação da existência de uma peripécia historiográfica. Vale destacar que, em texto muito recente, um dos principais historiadores do teatro brasileiro afirmou, em termos tão sucintos quanto objetivos, que o ator "permaneceu" graças à sua genialidade (MAGALDI, 2008, p.10).

A rigor, apesar do sucesso da montagem de 1959, a revisão do significado da obra de Artur Azevedo começou no final dos anos 1970, início dos anos 1980. E foi uma mudança da academia, digamos. Dentre os primeiros gestos de recuperação, figuram os estudos e a dedicação do Professor Antonio Martins, editor de suas obras na Coleção Clássicos do Teatro Brasileiro, em sua origem um projeto do Serviço Nacional de Teatro sob a gestão lúcida de Orlando Miranda, um projeto excelente em má hora abandonado pela FUNARTE nas administrações seguintes. O primeiro volume foi publicado em 1982. Uma vasta busca por originais e edições começou a ser realizada, com apoio do filho do comediógrafo, Aloísio Azevedo Sobrinho, ainda vivo então. A listagem de sua obra já atinge hoje números admiráveis. Mas, nos sucessivos levantamentos do pesquisador Antonio Martins, é espantosa a quantidade de originais perdidos. É uma tarefa curiosa cotejar as diferentes enumerações de suas obras - bem distantes ainda de figurarem sob o rótulo de completas - nos sucessivos róis elaborados. Talvez nunca se consiga chegar a definir com exatidão a listagem de todas as obras de sua autoria, mesmo que se pretenda enumerar só os textos de teatro.

Um dos títulos mais curiosos desta vasta obra também foi herói de incontáveis peripécias - o Pum!, opereta de 1894, cujo tema central é a Revolta da Armada. O 
manuscrito da obra surgiu, sumiu e reapareceu novamente, em tais movimentações que permanece inédito ainda hoje, nunca foi publicado. Na lista de manuscritos incluída no volume de 1982, dedicado ao seu teatro e organizado por Antonio Martins, ele aparece em último lugar, como o único elemento da Coleção do ator Ângelo Labanca. Ao que parece, o manuscrito teria sido doado pelo ator à atriz Fernanda Montenegro, que o repassou ao crítico Sábato Magaldi, para ser doado à Academia Brasileira de Letras.

Neste percurso, o seu rastro sumiu dos editores e o desaparecimento fez com que deixasse de ser incluído nas coleções publicadas, muito embora alguns pesquisadores cogitem a hipótese de existência de um outro exemplar. $\mathrm{Na}$ reedição de suas peças de teatro pela FUNARTE, de 2002, o texto não foi incluído. A hipótese de existência de mais de um exemplar perdido, vagante, justificaria o vasto folclore - ou anedotário - de aparições e sumiços. Na edição de 2002, o seu título aparece apenas na listagem das obras em parceria com Eduardo Garrido, com a indicação sumária “opereta Pum! [1894], sobre a Revolta da Armada, reencontrada recentemente”...

O estudo desenvolvido aqui é uma pequena parte de uma tarefa de grande extensão. As dimensões necessárias ultrapassam em muito o formato deste artigo, até mesmo em razão da história do gênero e do original, rapidamente esquematizadas acima; seria necessário desenvolvê-las bem mais. O que se tentou fazer é um esboço modesto, uma sugestão tímida; não passa de uma primeira abordagem, bastante singela. Trata-se de expor o resultado de um estudo de aproximação que será necessário ampliar - este é o registro do início de uma pesquisa. Apesar destes limites, mesmo sob um primeiro enfoque, parece essencial examinar o tema em uma dupla chave de leitura - a inserção do dramaturgo na História do Teatro e em sintonia com o contorno dominante nas histórias do teatro brasileiro e, em paralelo, a análise da peça, em sua densidade específica e em função das tradições dos estudos de dramaturgia.

Neste sentido, a primeira observação importante a fazer é em relação ao título - a escolha surpreendente, a um só tempo ousada e jocosa, demolidora mesmo, é muito forte. Soa como uma espécie de desmentido aos argumentos de Décio de Almeida Prado, de que o autor guardaria uma envergadura de homem erudito interessado em mostrar os contornos da plebe, mas preservando a sua postura acadêmica. Ainda hoje, depois de mais de um século, é difícil pronunciar livremente o título sonoro sem causar estranheza ou constrangimento. Quem titula uma peça com um simples Pum! não está rendido aos encantos ou ao domínio da norma culta e é razoável que muitos dos admiradores do autor, mais formais ou conservadores, tenham desejado que a obra simplesmente não existisse, parasse de incomodar com a mera irreverência do nome, constrangedor para algumas suscetibilidades.

Uma rápida consulta aos dicionários dimensiona o impacto da escolha. $\mathrm{O}$ vocábulo não consta nem no Moraes (1813), nem no Séguier (1910). Também ainda não fazia parte do Koogan Larousse (1980), assim como não foi incluído no AuleteValente (1881), mas apareceu no Laudelino Freire (1957) apenas como interjeição, "voz que serve para exprimir o ruído de uma queda ou de uma explosão" (p. 4200). 
Nos principais dicionários contemporâneos - Aurélio (1986) e Houaiss (2001) - a palavra tornou-se corrente, identificada como de uso familiar: além da interjeição e da onomatopéia, registra-se uma nova acepção, sinônimo de peido, traque.

Evidentemente Artur Azevedo escolheu o seu título com o olhar na sinonímia de todos conhecida. E o objetivo político era claro - marchava ao lado das massas populares que aclamavam Floriano e repudiavam os monarquistas, ou todos aqueles que pretendessem desestabilizar a mão de ferro que tentava manter em ordem o governo da república recém proclamada. Como demonstrou Raimundo Magalhães Júnior, Artur Azevedo era florianista e o seu biógrafo chega ao ponto de afirmar que ele foi o DIP de Floriano, quer dizer, o Departamento de Imprensa e Propaganda, um ser humano transformado em um dispositivo de propaganda, semelhante ao órgão do governo que se incumbira de transformar mais tarde o caudilho Getúlio em mito popular.

Há, portanto, um objetivo claro na peça, imediato, que é o de ridicularizar os opositores de Floriano e do governo constituído, responsáveis pela Revolta da Armada e pela ousadia de tentar fazer de refém a cidade e a população. Esta deliberação faz com que o contorno geral da trama atenda a certo cálculo preciso. É curioso observar como o texto se estrutura, como a dramaturgia funciona a partir do objetivo previamente fixado.

Ainda não existem estudos específicos sobre a opereta brasileira; sobre a burleta, objetivamente sobre $A$ Capital Federal, Décio de Almeida Prado (1986, pp.276280) demonstrou a sua natureza híbrida - "...é uma síntese das melhores qualidades do nosso teatro musicado,(...) uma amálgama, não simples mistura, que prima pela brasilidade e pela unidade." Não seria uma colcha de retalhos "tecida com gêneros díspares e sobras de peças estrangeiras." Ali se tecia o novo e se apresentava um palco de invenção.

Algo semelhante talvez possa ser dito sobre a opereta nacional, ao menos para a compreensão da dinâmica interna de Pum!. A rigor, a estrutura desta opereta aparece contaminada, pois o espetáculo estrutura-se a partir de uma trama, à diferença do contorno convencional originário da opereta, francês, que Pougin (1885, pp.567568) definiu a partir da música, e que foi a grande referência para o palco brasileiro e para o teatro de Artur Azevedo.

Segundo o estudioso francês, a palavra surgira no século XVIII para falar de uma composição musical ligeira, fácil, rapidamente esquematizada, integrada apenas por canções frias e couplets de vaudeviles; aos poucos, no boulevard, ela se ampliou e ganhou o gosto popular, mas só após o decreto de 1864, que liberou os teatros dos entraves e limitações que o engessavam, a opereta passou na França a ter 3 atos e se espalhou por diversas casas, tornando-se uma indústria próspera. Portanto, tratavase justamente de um espetáculo de representação em que o motor era a música, uma música capaz de falar e arrebatar as sensações, digamos, corporais, o frisson.

É bem verdade que Artur Azevedo, em luta contra a pretensão impertinente de alguns literatos de sua época, de que a opereta deveria ser instrumento para regeneração do teatro nacional, chegou a afirmar com ênfase que os libretos de opereta 
não tinham - e nem poderiam ter - veleidades literárias, pois não passavam de meros pretextos para a música. Mas este ponto de vista não pode ser sustentado com facilidade diante deste original, já que o próprio título pesa a favor de um entrecho de dupla extração, a saber o episódio histórico que sacudira a cidade e a opção política de achincalhe dos revoltosos. Portanto, ainda que não se tenha a localização da partitura de Pum! para afiançar sobre o peso da música, o estudo do libreto não permite dizer que ele seria 'mero pretexto', pois a sua espessura é de outra ordem. De saída, o libreto olhava para fatos urgentes do momento, uma cidade e um país em pé de guerra, por mais desequilibrados que fossem os lados em conflito.

Estamos, assim, diante de uma escritura dramatúrgica que remete à estrutura da revista de ano e traz à lembrança o jogo cênico da burleta. Se não se pode falar exatamente que haja um recurso à técnica da cena aberta (MENCARELLI, 1990, pp.162 e segtes) - quer dizer, ampla exposição e confronto de opiniões que refletem o panorama da vida urbana, procedimento corrente na revista de ano, pois o conjunto todo da peça é florianista - persiste ainda assim a idéia de tribuna, digamos, no sentido de que as diferentes personagens populares revelam... o seu alheamento frente ao cenário político, se expõem como parte da vida pulsante da cidade. Em lugar de debate e confronto, diante da revolta predomina a surpresa, o divertimento e até mesmo certo fastio e alguma irritação. Em larga medida as pessoas expressam suas formas de pensar, seus modos de vida e suas necessidades, sem que saibam dizer claramente de que lado estão ou o quê, de verdade, acontece na cidade.

Há portanto um ancoramento da peça na dramaturgia, tecida com fatos que são sensacionais por si. Em cena, surge algo capaz de despertar o interesse com ímpeto, algo que se torna eficiente o bastante para se impor sem o recurso da música. $\mathrm{O}$ centro de atração é a referência à vida trepidante, em todos os sentidos, que a população é obrigada a viver. Este núcleo foi construído, por sua vez, como estrutura binária - uma solução técnica aparentada com os "dois estágios de ações diferentes" que coexistem na revista de ano, o estágio do fio condutor e o dos quadros episódicos, em que algumas personagens se deslocam o tempo todo, recurso para que possam percorrer os diferentes quadros isolados (VENEZIANO, 1991, p.88).

No Pum! há uma trama central, ao redor da família de Anacleto, modesto funcionário público, cuja mulher, Engrácia, precisa fabricar balas, vendidas por um moleque negro de ganho, para ajudar nas despesas da casa. Eles moram no Morro do Castelo, ao lado da venda do Joaquim, com quem Anacleto deseja casar a filha Lainha, para a vida melhorar, pois passaria a contar com os suprimentos da venda do genro. Mas Lainha pensa diferente, ela namora escondido o jovem Cazuza e conta com a mulata Mônica, empregada e agregada da casa, como alcoviteira que, por sua vez, sonha casar com o português Joaquim. Evidentemente o português prefere o "café com leite" e também mantém um romance às escondidas, com a cabrocha. Como trama auxiliar para o desenlace deste núcleo, há a história de três amigos de pândega que a vida dispersou no mundo e que, no final, por acaso e em boa parte por causa dos tiros dos navios, acabam se reencontrando, para viabilizar os dois casamentos dos apaixonados... 
Ao lado desta trama central, que envolverá a realização de um casamento falso de Lainha e Joaquim, no civil, por artes do jovem apaixonado, há um outro fluxo de ação, a História propriamente dita, a Revolta da Armada, figurada pelo dramaturgo como se fosse uma reportagem vivida bem humorada. Quando o pano abre, já estão os navios rebelados na Baía de Guanabara, atirando contra a cidade; logo os moradores do Morro do Castelo são envolvidos pelos bombardeios e chegam à conclusão de que é preciso fugir. Partem para a Tijuca, na época um local bastante ermo e bucólico. Há na peça, para o nosso olhar de hoje, uma cidade fantasma, pois ela desapareceu - não há mais nem o Morro do Castelo, nem a Tijuca das chácaras e do isolamento bucólico. Esta estrutura binária, a exposição paralela da trama de comédia e da História, permite no texto um arranjo sui generis - a exposição curiosa de uma dupla que caminha lado a lado mas que se ignora, o povo e a história.

A distância entre os dois universos é explorada como efeito cômico em diversas passagens, nas quais fica patente que o que move o povinho é o boato e que a população não tem idéia precisa do que acontece. No princípio da ação, fala-se na possibilidade de bombardeio, mas ninguém sabe ao certo o que pode acontecer e a hesitação será explorada durante toda a peça graças a um gesto cômico do português, que manda tirar ou colocar as cebolas penduradas na porta da venda, conforme a opinião oscila entre o anúncio de provável bombardeio ou a sua negação. Há ainda a brincadeira com a palavra torpedeira, que aparece em uma boca como trepadeira e, em outra, tropedeira. E com a palavra encouraçado, que seria o caixeiro com um couro sob as vestes, para não sofrer com os pontapés que costuma receber...

Ao longo dos três atos e 6 quadros, muitos são os números musicais, mas o original poderia ser apresentado quase sem música - quer dizer, a ação se estrutura independemente das partes musicais. Uma única canção, no final do primeiro ato, o ápice da ação, tem função dramatúrgica explícita - é uma "copla e coro" em que a jovem Lainha tenta atrasar a cerimônia do casamento religioso, para ver se o seu amado arranja um meio para impedir o desenlace, pois ele já tinha feito a pouco um casamento civil falso. Logo ao final do número, começa o bombardeio da cidade, que atinge o morro, e há uma enorme confusão no palco. Quer dizer, em sua maior parte, as músicas funcionam no papel de comentários ou adendos, declarações de intenções, fechamentos ou aberturas de cena. Há até mesmo um número musical caricato, o Fandangoapum, um tango que comenta o gosto da população em ir até a praia para ver "o troar do canhão", o que efetivamente aconteceu, pois o povo ia para a murada do Passeio Público divertir-se com a dificuldade dos navios de guerra revoltosos para acertar fosse o que fosse com os seus tiros. Assim, os atores não precisam ser cantores, podem ser atores que cantam, pois o canto não é o condutor do espetáculo.

No segundo ato, a ação começa na paz de uma confortável sala na Tijuca. Após a chegada do primeiro fugitivo, Saraiva, velho amigo do dono da casa (Bibiano) e amante secreto de sua mulher, há um diálogo curioso entre os dois, pois indica 
também o grau de alheamento frente à política professado por setores mais abastados:

Bibiano - Sim, consta-me que há perto de um mês há aí uma revolta. Ouço os tiros ao longe. Não quero saber disso... não tenho partido!

Saraiva - A coisa hoje esteve feia. Um balasio do Aquidaban deitou abaixo a torre da igreja da Lapa dos Mercadores! Caíram casas... Morreram algumas pessoas.

O dono da chácara expõe largamente o seu desinteresse pelo fato, a sua inclinação pelo mato e pela solidão, uma preparação minuciosa para o efeito cômico que se seguirá, com a casa invadida por uma leva de desconhecidos que vai se alojando por toda a parte e xeretando tudo. Amante dos balões, ele expõe o delírio que persegue - tornar-se o herói capaz de completar a obra de Bartolomeu de Gusmão e voar pelos ares... Após a definição do ermitão como maluco e do romance que une o amigo à sua mulher, explicitado pela dupla quando Bibiano sai de cena, começa o desfile impagável de retirantes populares, inclusive as personagens do primeiro ato. A solução viabiliza o recurso a piadas e cenas de comédia episódicas, localizadas, com freqüência independentes, dissociadas tanto da ação central articulada ao redor dos moradores do Morro do Castelo, quanto do fio da História, um pouco como se fossem as cenas independentes das revistas.

O desfecho da peça se faz a partir do cancelamento do casamento de Lainha e Joaquim - na Tijuca, Cazuza consegue fazer com que o grupo surpreenda uma entrevista entre o português e a mulata. Por conta de suas aprontações, o rapaz acabou alistado na Guarda Nacional, por interferência de Anacleto. Mas a providencial chegada do padrinho do rapaz no Morro do Castelo, um velho conhecido de Anacleto, com quem ele perdera contato, permite o final feliz entre os dois jovens namorados e a peça acaba com duplo casamento e a sugestão de que se repita o Fandangoapum.

É surpreendente a habilidade do texto. A mistura entre história presente e trama de sátira ao cotidiano do momento é uma escolha de rara felicidade. Não importa, diante de uma obra desta envergadura, discutir uma possível classificação de acordo com uma visão hierarquizada de gêneros, de resto ultrapassada. Antes de tentar saber se a peça registra o movimento intelectual mais abstrato ou formal da época, vale a pena estudá-la, para dimensionar algumas das surpresas que Artur Azevedo assinou, ao aproximar apaixonadamente o palco da pulsação da vida em seu tempo.

\section{Bibliografia}

AZEVEDO, Arthur. Teatro de Arthur Azevedo. Vol. I. Rio de Janeiro: SNT, 1982

. Teatro de Artur Azevedo. Coleção Clássicos do Teatro Brasileiro. Vols. IV e V. Rio de Janeiro: FUNARTE, 2002.

. Pum! Exemplar em cópia de manuscrito da Coleção Ângelo Labanca.

MAGALDI, Sábato. Teatro em foco. São Paulo: Perspectiva, 2008.

MAGALHÃES JR., R. Arthur Azevedo e sua época. Rio de Janeiro: Civilização Brasileira, 1966. 
MARTINS, Antonio. Artur Azevedo: a palavra e o riso. São Paulo: Perspectiva, Rio de Janeiro: Universidade Federal do Rio de Janeiro, 1988.

MENCARELLI, Fernando Antonio. Cena aberta. A absolvição de um bilontra e o teatro de revista de Artur Azevedo. Campinas: Editora UNICAMP, 1999.

PRADO, Décio de Almeida. "A Evolução da literatura dramática”. Coutinho, Afrânio (org). A literatura no Brasil. 2 ed. Rio de Janeiro: Sul Americana, 1971, pp. 7-37. , História concisa do teatro brasileiro São Paulo: EDUSP, 1999.

, Posfácio - "Do Tribofe à Capital Federal". In. Azevedo, Artur, O Tribofe. Rio de Janeiro: Nova Fronteira/Fundação Casa de Rui Barbosa, 1986.

SOUSA, Galante. O teatro no Brasil. Rio de Janeiro: INL, 1960.

SUSSEKIND, Flora. As revistas de ano e a invenção do Rio de Janeiro. Rio de Janeiro: Nova Fronteira/ Fundação Casa de Rui Barbosa, 1986.

VENEZIANO, Neyde. O teatro de revista no Brasil. Dramaturgia e convenções. Campinas: Pontes Editores, 1991.

\section{Dicionários}

Aulete-Valente. Diccionario Contemporâneo. Lisboa: Imprensa Nacional, 1881.

Ferreira, Aurélio B. de Holanda. Novo dicionário da língua portuguesa. Rio de Janeiro: Nova Fronteira, 1986.

Houaiss, Antônio e Villar, Mauro de Salles. Dicionário Houaiss da Lingua Portuguesa. Rio de Janeiro: Objetiva, 2001.

Koogan-Larousse. Pequeno Dicionário Enciclopédico. Rio de Janeiro: Editora Larousse, 1980.

Laudelino Freire. Grande e Novíssimo Dicionário da Lingua Portuguesa. Rio de Janeiro: José Olympio, 1957.

Silva, Antonio de Moraes. Diccionario da Lingua Portugueza. Lisboa: Typographia Lacerdina, 1813.

Séguier, J. Diccionário pratico e ilustrado: novo diccionário encyclopedico luso-brasileiro. Lisboa: Emp. Diccionário Prático Ilustrado, 1910. 